\title{
Ship Berthing Safety Assessment Based on Ship-Handling Simulator
}

\author{
Geng Hejun, Fan Fuquan, Jiang Xiaobin*, Wang Deling, Tao Qingfeng \\ Merchant Marine College, Shanghai Maritime University, Shanghai, China \\ Email address: \\ genghj@shmtu.edu.cn (Geng Hejun), fanfq@shmtu.edu.cn (Fan Fuquan), xbjiang@shmtu.edu.cn (Jiang Xiaobin), \\ dlwang@shmtu.edu.cn (Wang Deling), qftao@shmtu.edu.cn (Tao Qingfeng) \\ ${ }^{*}$ Corresponding author
}

\section{To cite this article:}

Geng Hejun, Fan Fuquan, Jiang Xiaobin, Wang Deling, Tao Qingfeng. Ship Berthing Safety Assessment Based on Ship-Handling Simulator. American Journal of Traffic and Transportation Engineering. Vol. 6, No. 1, 2021, pp. 10-21. doi: 10.11648/j.ajtte.20210601.12

Received: February 6, 2021; Accepted: February 17, 2021; Published: February 26, 2021

\begin{abstract}
As the development of ship building technologies, ships have been becoming larger and larger. As a result, the existing ports and waterways can not meet the requirements of safe navigation, berthing and unberthing operations of large ships. In order to ensure the safe berthing and unberthing for large ships, wharf and waterways need to be rebuilt, also it is necessary to check whether the rebuilt wharf can meet the navigation needs. In this paper, the ship handling simulator is used to simulate the safe berthing and unberthing of the pier. This paper establishes the mathematical model of ship motions, generates virtual navigation environment, applies the concepts of track zone width, potential ship handling water area, utility function and risk of berthing operation, and makes a comprehensive analysis of the width of the channel, ship manoeuvring waters and the safety of berthing operation, and puts forward some objective and reasonable suggestions on the safety of berthing. By practical application of ship-handling simulator to evaluate the safety of ship berthing and unberthing, it shows that the method based on ship-handling simulator is objective, feasible and reasonable to analyze and evaluate the navigation safety of wharf engineering, and has a good value of application.
\end{abstract}

Keywords: Ship Handling, Simulator, Berthing Operation, Navigable Environment, Safety Assessment

\section{Introduction}

Ports and their sustained and stable development are the basic guarantee of economic prosperity in coastal areas. At present, with the increasing scale of coastal port construction, the number and tonnage of incoming and outgoing ships are increasing, and the traffic conditions of port and waterway are becoming more and more busy. A large number of accident statistical analysis shows that the ports and their nearby waters are the areas where maritime traffic accidents often occur, which have a great impact on the development of port safety, security and ecological environment [1]. Therefore, the China Maritime Safety Administration (MSA) requires that the proposed port construction waters must be evaluated for the safety of navigation to ensure the safety of ship navigation and berthing operation in the proposed construction waters and nearby.

Based on the application requirements of port waterway navigation safety evaluation, a large ship handling simulator is used to simulate the ship berthing operation. It is necessary to establish a mathematical model of ship motion to study ship berthing safety. The study of mathematical model of ship movement began in the 1930 s, when major shipbuilding countries built a large number of equipment to determine the hydrodynamic derivative of ships [2]. The research of ship hydrodynamic model is mainly divided into two sects: the integral model represented by Abkowitz [3] and the separated model proposed by the Japanese ship handling motion mathematical model research group (Maneuvering Mathematical Modeling Group, MMG) [4]. Although the integral model can achieve high accuracy, its application range is small, and the physical meaning of some polynomial coefficients in the model is not clear. The physical meaning of each variable in the separation modeling method is clear, and the mathematical model of ship motion obtained by the MMG model is also quite accurate, so the MMG model has been widely used in the world. Many scholars are still based on the MMG model to establish ship motion models and 
calculate hydrodynamic parameters $[5,6]$.

In this paper, the idea of separation modeling is used to establish the motion mathematical model of 70,000 tons bulk carrier, and the feasibility of the model is verified by experiments. After that, the design width of the safe navigation channel and the critical condition of the wharf are analyzed, and some reasonable suggestions on navigation safety and ship berthing safety are put forward.

\section{Design of Test Scheme}

Among the main factors to evaluate the safety of navigation are the width, water depth, navigation conditions and net height of navigation waters [7]. These factors are also affected by ship speed, rudder angle, ship handling performance, tug power and quantity, wind and tide and other external conditions, operator's skills and so on. The existing ship handling simulator has integrated ship navigation related instruments and equipment, and the evaluation of navigation safety based on ship control simulator has been widely recognized by the industry.
The preparation of navigation evaluation using ship handling simulator is as follows: 1) collect the local information needed for investigation, including: charts, preliminary design, wind, current, tide and other hydrological, environmental, meteorological data, etc.. 2) making electronic charts of the test sea area. 3) go to the scene to take photos, videos, and build a three-dimensional view on the computer. 4) establish the model data of the required ship, etc.

After the preparation is ready, the preliminary test plan is drawn up according to the purpose of the evaluation test and the practical experiences of the pilots and ship masters who are familiar with the field environment. Considering the most adverse effects of various environmental factors, carry out the test plan, and analyze the test results statistically, and then put forward reasonable suggestions according to the statistical results [8]. The whole port waterway and navigation safety evaluation process of the wharf is shown in Figure 1. Then, by using ship handling simulator, the navigation and berthing safety of Ningbo Guanbao wharf in China is demonstrate

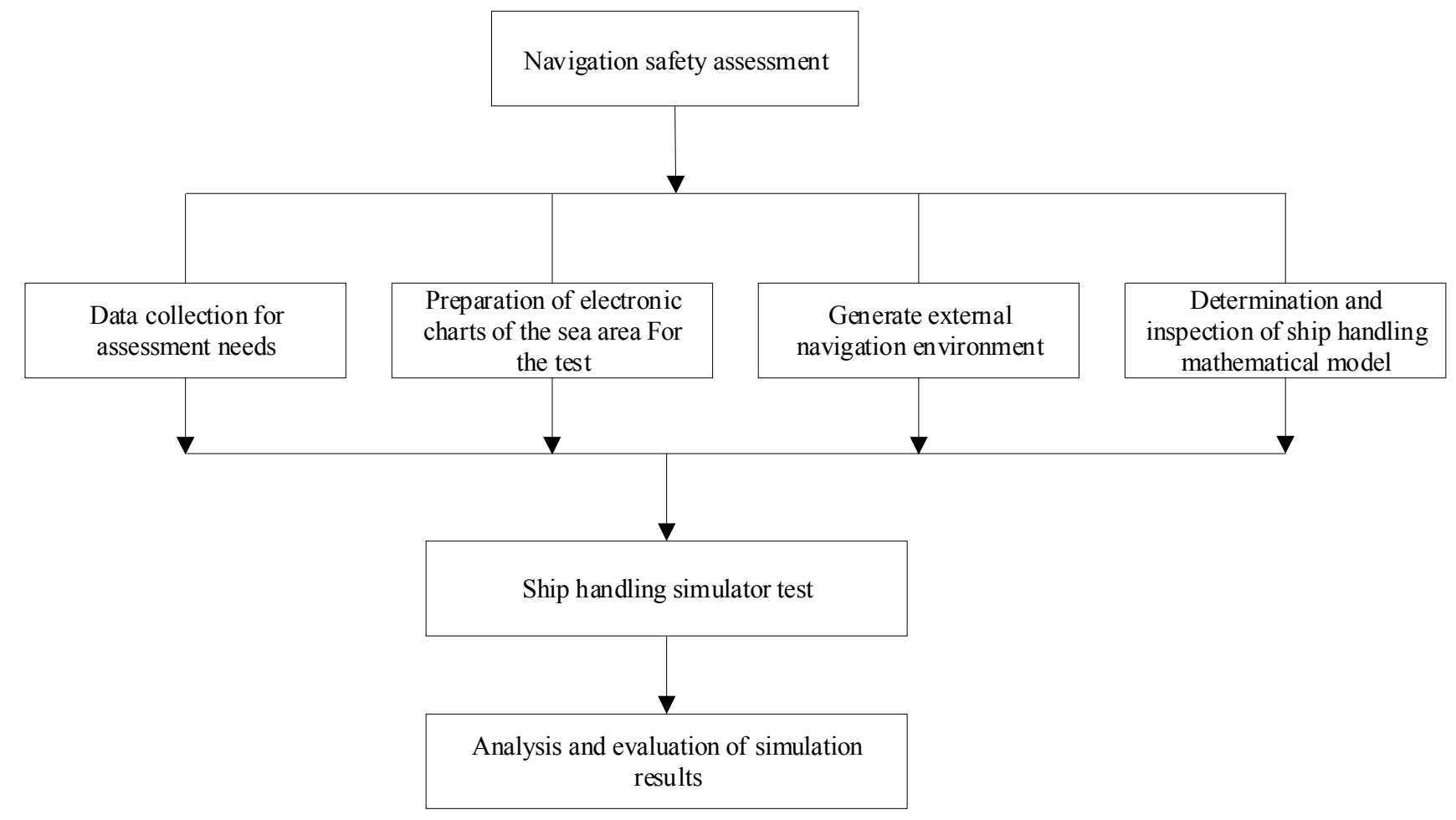

Figure 1. Port Channels and Wharf Safety Assessment Process.

\section{Ship Motion Model}

The ship motion model is the core of the safety demonstration by using simulators. According to the navigation and berthing capacity of Ningbo Guanbao Wharf, the ship motion model was designated as a bulk carrier of 70,000 tons for the test. This paper, taking M.V. "Hai Qing" as the simulation object, established the ship motion model and verified by simulation.

\subsection{Ship Plane Motion Equation}

To study the movement of ships, the spatial inertial coordinate system $\mathrm{X}_{0} O Y_{0}$ and the ship moving coordinate system $X G Y$ are established, as shown in Figure 2. The original point of the spatial inertial coordinate system is a point on the water surface $O$, the axis $X_{0}$ points to the north and $Y_{0}$ to the east The origin of the ship moving coordinate system is taken at the center of gravity of the ship, the axis $X$ points to the bow direction, and the axis $Y$ is perpendicular to 
the ship's center line fore and aft and points to the starboard of the ship.

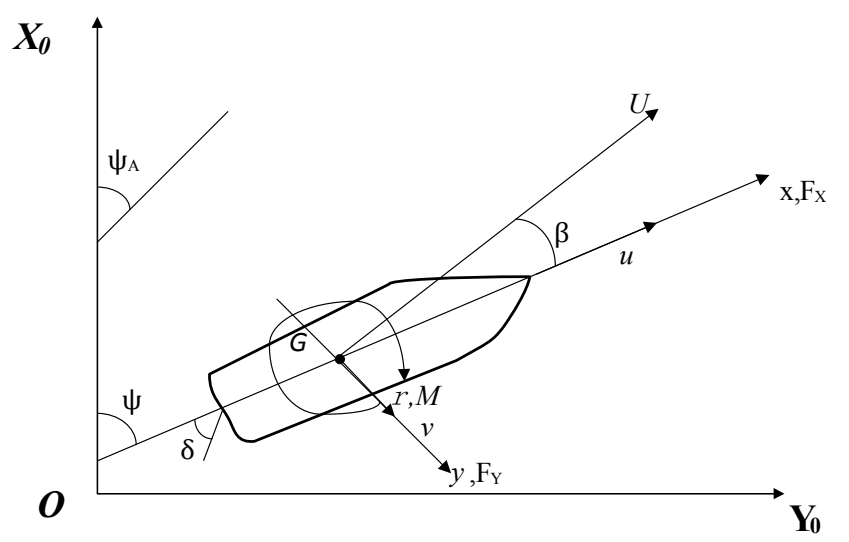

Figure 2. Schematic diagram of ship motion coordinate system.

According to the MMG separation modeling idea, the ship's plane motion equation can be expressed in the ship's coordinate system as the following, and the various forces and moments acting on the ship are calculated according to the forces and moments of the bare hull, propeller, rudder, wind, flow and so on [9]9].

$$
\left\{\begin{array}{l}
\left(m+m_{x}\right) \dot{u}-\left(m+m_{y}\right) v r=X_{H}+X_{R}+X_{P}+X_{\mathrm{Env}} \\
\left(m+m_{y}\right) \dot{v}+\left(m+m_{x}\right) u r=Y_{H}+Y_{R}+Y_{P}+Y_{\mathrm{Env}} \\
\left(I_{z z}+J_{z z}\right) \dot{r}=N_{H}+N_{R}+N_{P}+N_{\mathrm{Env}}
\end{array}\right.
$$

In the equation, $m$ is the quality of the ship, which can be obtained by the $m=\rho \nabla ; \quad \rho$ is sea water density, taking $1025 \mathrm{~kg} / \mathrm{m}^{3} ; \quad \nabla$ is the displacement of the ship; $m_{x}, m_{y}$ is the associated mass of the ship moving in water; $I_{z z}, J_{z z}$ is moment of rotary inertia and associated moment of rotary inertia; $u 、 v 、 r$ is the longitudinal velocity, transverse velocity and angular velocity; Subscript $H, R, P$ represent the force and moment of hull, rudder and oar respectively; Subscript Env represents the interference force and moment of the ocean environment such as wind, wave and current to the ship.

\subsubsection{Wind Disturbance Model}

Wind produces wind pressure and moment on ship's structure above the ship's waterline. Assuming that the wind speed does not change with the height within the net height of the ship above the sea surface, the wind pressure and moment acting on the hull are calculated as the following model [10].

$$
\left\{\begin{array}{c}
X_{\text {wind }}=\frac{1}{2} \rho_{a} A_{f} V_{\text {wind }}^{2} C_{w x}\left(\alpha_{R}\right) \\
Y_{\text {wind }}=\frac{1}{2} \rho_{a} A_{s} V_{\text {wind }}^{2} C_{w y}\left(\alpha_{R}\right) \\
N_{\text {wind }}=\frac{1}{2} \rho_{a} A_{s} L_{\text {oa }} V_{\text {wind }}^{2} C_{w n}\left(\alpha_{R}\right)
\end{array}\right.
$$

In the equation, $\rho_{a}$ is the air mass density; $A_{f}, A_{s}$ is the frontal projection area and side projection area of ship above water line; $V_{\text {wind }}$ is the relative wind speed; $\alpha_{R}$ is the angle of wind to ship side; $C_{\mathrm{wx}}\left(\alpha_{R}\right), C_{\mathrm{wy}}\left(\alpha_{R}\right)$ and ${ }_{\mathrm{wn}}\left(\alpha_{R}\right)$ is the wind pressure coefficient and the moment coefficient of wind pressure in ship longitudinal and transverse direction.

\subsubsection{Current Disturbance Model}

The current is another kind of disturbance encountered by the ship when sailing at sea. The current can affect the course, speed and position of a ship, or cause the ship to swing. The current is relatively stable during mooring operation. It is generally assumed that the current is a constant uniform flow, that is, the velocity and flow direction do not change with time and position. The effect of water flow on ship motion is equivalent to changing the relative velocity between ship's hull and water. For calculating the hydrodynamic force and moment of the hull and the hydrodynamic force and torque produced by the propeller and rudder, the relative water velocity is used instead of the ship's ground velocity, then the ship's relative water velocity $\left(u_{r}, v_{r}\right)$ and acceleration $\left(\dot{u}_{r}, \dot{v}_{r}\right)$ are:

$$
\begin{gathered}
\left\{\begin{array}{l}
u_{r}=u-V_{\text {current }} \cos \left(\psi_{\text {current }}-\psi\right) \\
v_{r}=v-V_{\text {current }} \sin \left(\psi_{\text {current }}-\psi\right)
\end{array}\right. \\
\left\{\begin{array}{l}
\dot{u}_{r}=\dot{u}-r V_{c} \sin \left(\psi_{c}-\psi\right) \\
\dot{v}_{r}=\dot{v}-r V_{c} \cos \left(\psi_{c}-\psi\right)
\end{array}\right.
\end{gathered}
$$

In the equation, $V_{\text {current }}$ is the current velocity; $\psi_{\text {current }}, \psi$ is the current direction and heading respectively.

\subsection{Model Simulation and Verification}

Taking the M.V. "Haiqing" of 70,000 tons bulk carrier as the research object, the mathematical model of ship motion is established, and a series of simulation tests are carried out. The principle particulars of "Haiqing" are shown in Table 1.

Table 1. Test ship model and main parameters.

\begin{tabular}{ll}
\hline Parameters & Value \\
\hline Ship's name & HAI QING \\
Length overall & $225 \mathrm{~m}$ \\
Beam & $32.26 \mathrm{~m}$ \\
Loaded draft & $13.8 \mathrm{~m}$ \\
Ballast draft & $6.5 \mathrm{~m}$ \\
Dead weight & $73288 \mathrm{t}$ \\
\hline
\end{tabular}

\subsubsection{Turning Test and Analysis}

In the ship turning test, the wide and calm sea areas with smaller tidal current and sufficient depth are usually selected, so that the ship can first enter into the state of stable sailing motion, then steer to a fixed rudder angle, and after the transition stage, the ship will enter into the state of constant rotation motion.

The initial stable speed of the "Haiqing" in ballast condition is $15 \mathrm{kn}$, the initial course is $0.24^{\circ}$, the initial rpm is $115 \mathrm{r} / \mathrm{min}$ and the maximum rudder angle is $35^{\circ}$. The simulation results are shown in Figure 3. 

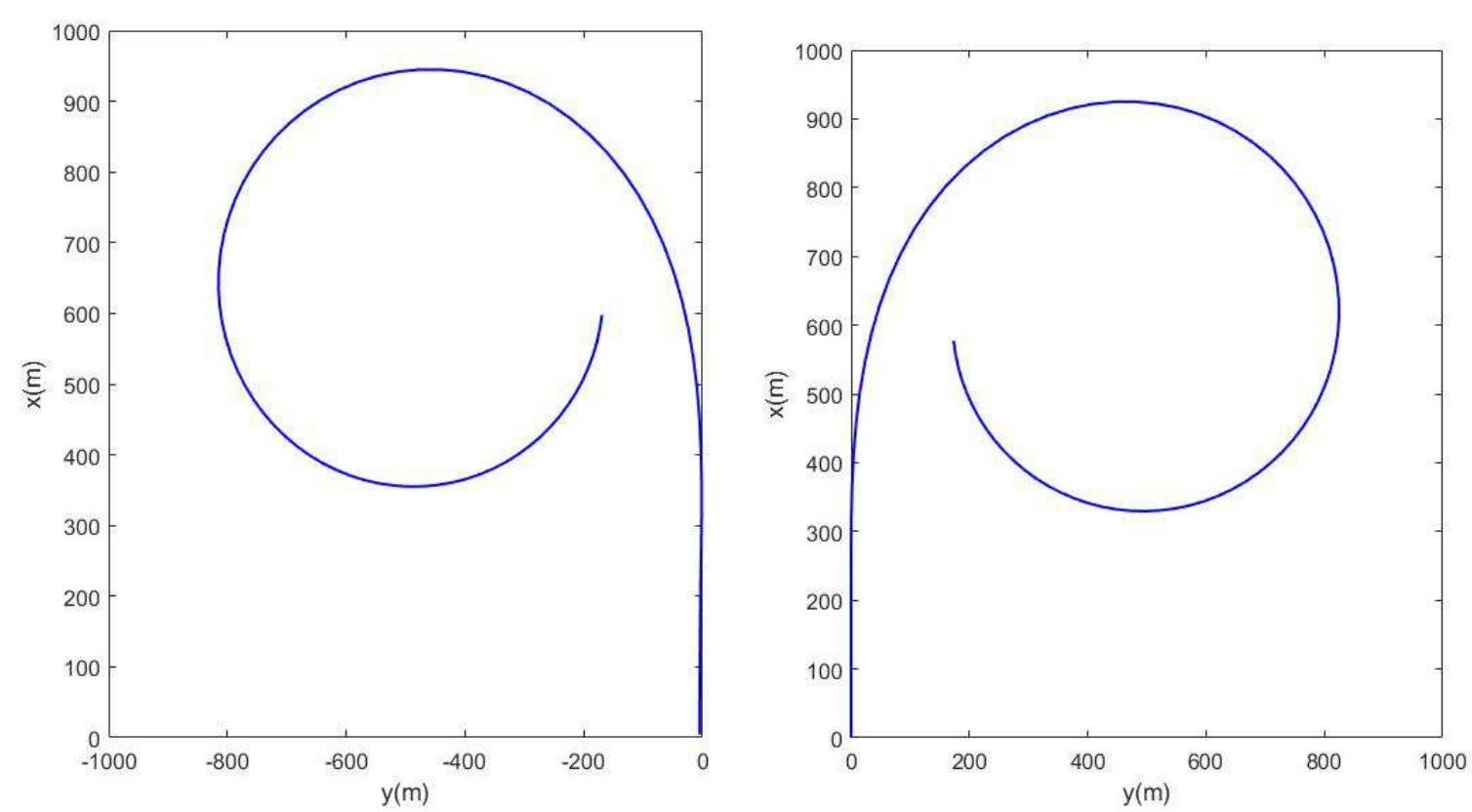

Figure 3. "Diagram of the track of the port and starboard turning test of "Haiqing".

Table 2. Comparison of the Simulation Results of Starboard Turing with the Results of the Real Ship Test.

\begin{tabular}{llll}
\hline Parameter & $\begin{array}{l}\text { Real ship } \\
\text { data }\end{array}$ & Simulation data & $\begin{array}{l}\text { Relative } \\
\text { error }\end{array}$ \\
\hline Advance $/ \mathrm{m}$ & 592.2 & 672.3 & $13.5 \%$ \\
Transverse $/ \mathrm{m}$ & 260.5 & 282.4 & $8.5 \%$ \\
Tactical diameter/m & 574.1 & 642.2 & $11.8 \%$ \\
Turning time/s & 516 & 540 & $4.65 \%$ \\
\hline
\end{tabular}

It can be seen from the relative error of Table 2 that the results of the ship's simulation test are in good agreement with the results of the real ship test, and the maximum error with the real ship test is $13.5 \%$, which can meet the precision requirements of the engineering and simulation.

\subsection{2. $Z$ Test and Analysis}

Wind 9kn (Beaufort Wind Force Scale 3), wind direction $000^{\circ}$. M.V. "Haiqing" sails at a constant speed of $15 \mathrm{kn}$ for a few minutes and then turn the rudder to to starboard $10^{\circ}$ for the first time; Keep this rudder angle $\delta$, when her heading deviates from the original direction $\psi$ to starboard $10^{\circ}$, immediately give the port $10^{\circ}$ rudder as the second steering; Keep the rudder angle at port $10^{\circ}$, the ship continues to turn in the original direction, but the turning rate will gradually decrease until the turning rate become 0 , and then the ship turns to the port side. When the heading is port $10^{\circ}$ to the initial heading, quickly put the rudder to starboard $10^{\circ}$ as the third steering. The above process continues until the completion of fifth steering, and when the ship is back to the initial heading, put the rudder to midships, and the test is over. The first overshoot angle obtained by ship's Z test simulation calculation in ballast condition is $2.6^{\circ}$ and the second overshoot angle is $3.2^{\circ}$. The curve of the simulation result is shown in Figure 4.

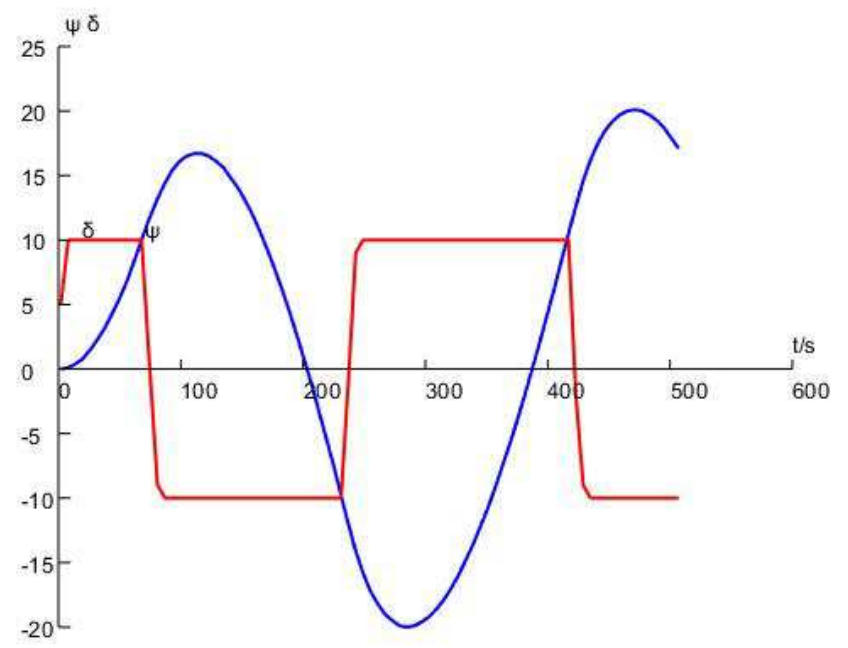

Figure 4. Simulation results of ship Z test (starboard $10^{\circ}$ ).

\subsubsection{Inertial Ship Stopping Test}

Inertial test is the process in which a ship stops her engine and her speed decreases from full speed (half speed) to the minimum speed at which she can keep her rudder effect (about $3 \mathrm{kn}$ ). Stopping test means that the ship reverses her engine from full sea speed. Stopping test refers to the test of the inertia travel, track and coasting time of the ship from full speed ahead to stop. A simulation of "inertial stopping test of M.V. Haiqing"at full speed is carried out. The simulation results are as follows:

$$
\text { Full speed } \rightarrow \text { stop }
$$

The initial heading of M.V. "Haiqing" in the test is $000^{\circ}$ and the initial speed is $15 \mathrm{kn}$. Regardless of the influence of the wind, the simulation results are shown in Figure 5. Figure 5(a) shows the track of the ship in the test, and the 
stooping distance is $3718.52 \mathrm{~m}$; Figure 5(b) shows the speed change of the ship in the test. The duration of the ship's speed from the initial speed of $15 \mathrm{kn}$ to the stoping speed of

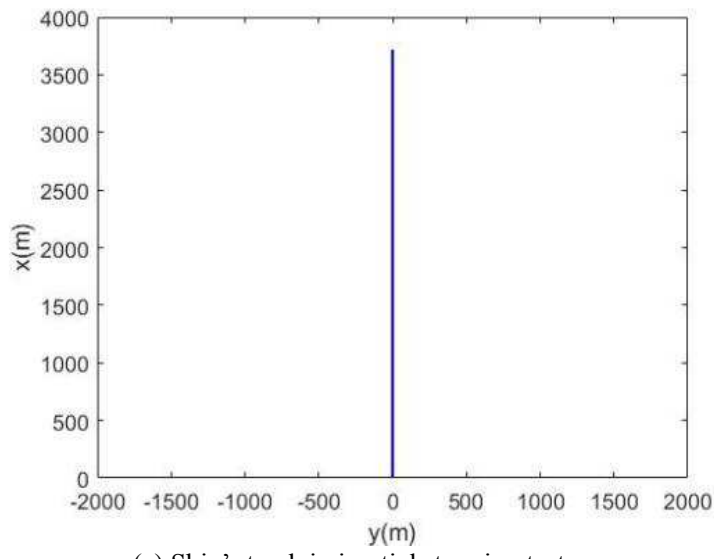

(a) Ship's track in inertial stopping test
$1.7 \mathrm{kn}$ lasts $1106 \mathrm{~s}$. The simulation results are compared with the real ship test results. The maximum error is $8.4 \%$. See Table 3 .

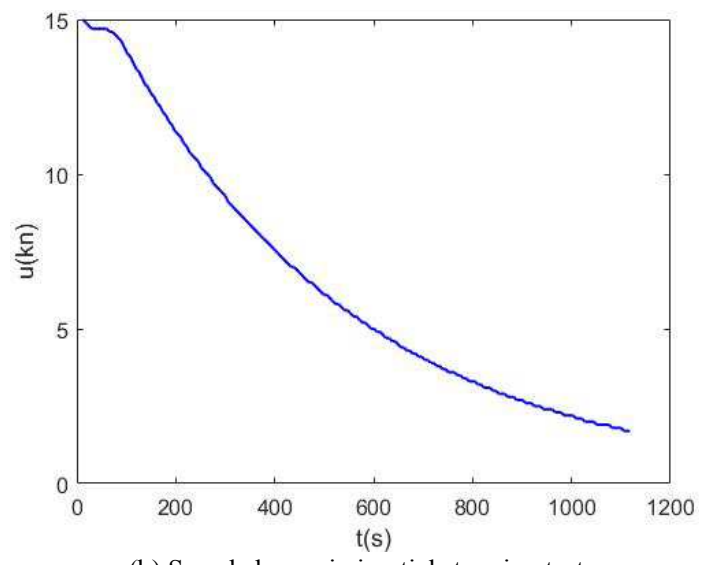

(b) Speed change in inertial stopping test

Figure 5. Simulation results of "Haiqing" full-speed stopping test.

Table 3. Comparison of simulation results with real ship test results of full-speed stopping of "Haiqing".

\begin{tabular}{llll}
\hline Parameter & Real ship test result & Simulation result & error \\
\hline Duration/s & 1020 & 1106 & $8.4 \%$ \\
Test distance/m & 3981.80 & 3718.52 & $6.6 \%$ \\
\hline
\end{tabular}

\section{Safety Assessment of ship Berthing Operations}

The factors that affect the ship's berthing operation are crew operation level, ship's own operation performance and navigation environment condition, etc. In this paper, the ship manoeuvring waters, traffic flow characteristics and berthing safety are taken as evaluation points to discuss the application of ship handling simulator test method in navigation environment safety assessment.

\subsection{Channel Conditions}

According to the of the "China Sea Port General Design Code (JTJ211-99) [11], The effective width of the channel $W$ is composed of the width of the ship's track $W_{T}$, the safety width between ships $W_{H}$, and the safety width between the ship and the edge of the channel $W_{C}$, as shown in Figure 6.

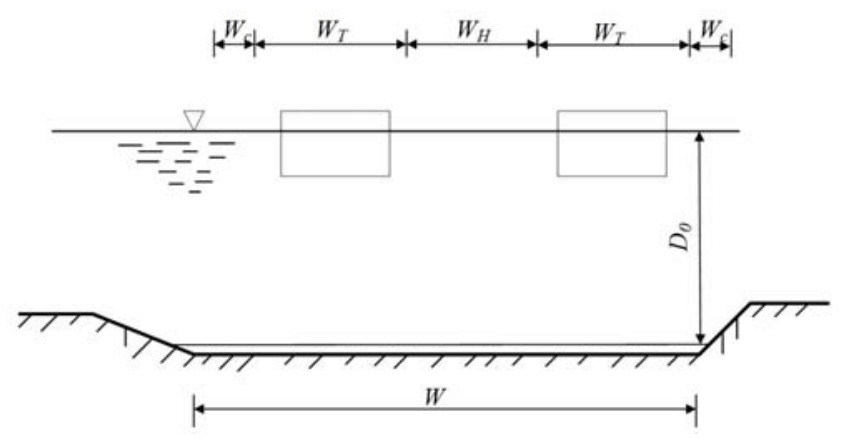

Figure 6. Effective Channel Width.
The factors affecting the determination of channel width include the maximum breadth of the designed navigable ship, the error between the real ship position and the calculated position, the additional width of the ship drift, and the additional width needed to correct the ship's deviation from the route. Applying the concept of potential ship-handling waters to analyze and evaluate the safety of ship handling, we can quantitatively express the the potential range of risk during the operation [12].

The following methods can be used to obtain potential ship-handling waters:

1) Obtain the motion parameters of the ship at certain intervals through the operation of the simulator.

2) Taking the given motion parameters as the initial condition and under the same environmental conditions, apply the set external environment, and obtain the ship's motion trajectory based on the ship's motion model.

3) Referring to the previous motion trajectory and data similar to the ship, the closed field formed by its trajectory is regarded as the potential ship-handling waters.

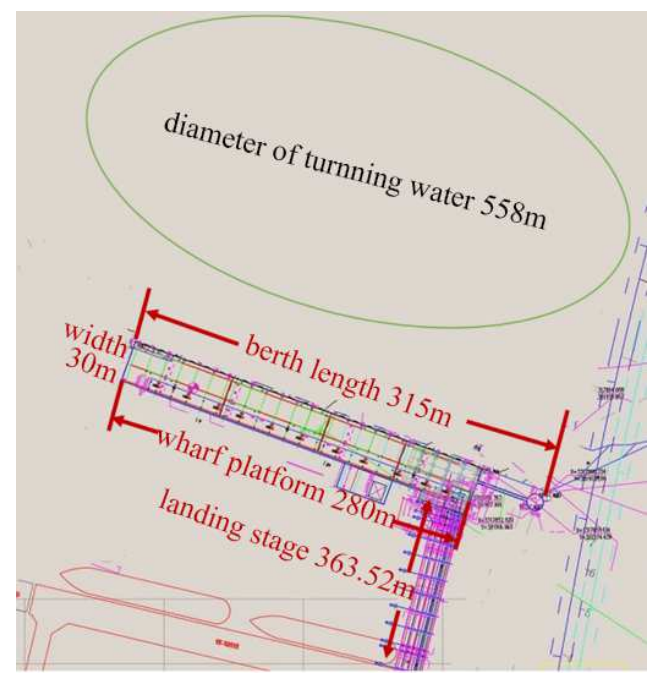

Figure 7. Layout of Ship-handling Waters at Guanbao Pier, Ningbo. 
This paper takes Guanbao terminal in Ningbo port, China, as analysis object. To calculate the turning waters of Guanbao terminal, the turning waters is designed as unprotected waters, the diameter of the turning waters is 558 $\mathrm{m}$, and the natural water depth in the turning area is larger than the design depth of the channel in the north. Figure 7 is an example of the simulation test condition and the required scale of turning area for a 70,000 tons bulk carrier, and the simulated test value of the ship's turning water scale is calculated by using the mean and variance.

The simulated test values are consistent with the trajectory of ship berthing and unberthing. The above method can be used to evaluate the safety and applicability of the ship turning water scale designed by wharf engineering.

\subsection{Analysis of Traffic Flow Characteristics}

Three observation sections were selected in a certain range near the pier, as shown in Figure 8. Based on the AIS flow data from $08: 00: 27$ on July 1,2016 to $07: 35: 24$ on July 1,2017 , the traffic flow through these three sections was counted [13], and the data are shown in Table 4.

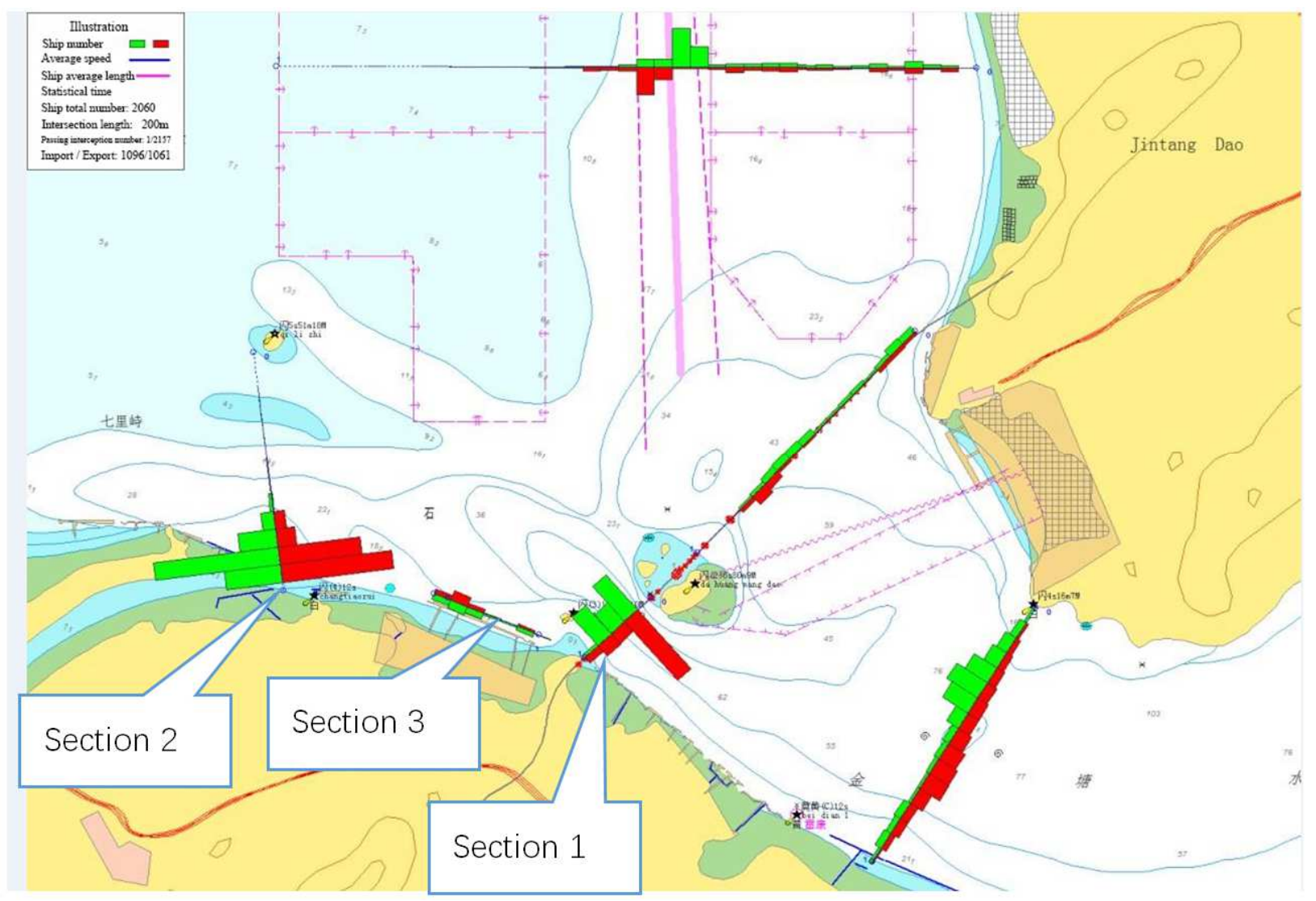

Figure 8. Traffic flow analysis near the Guanbao pier.

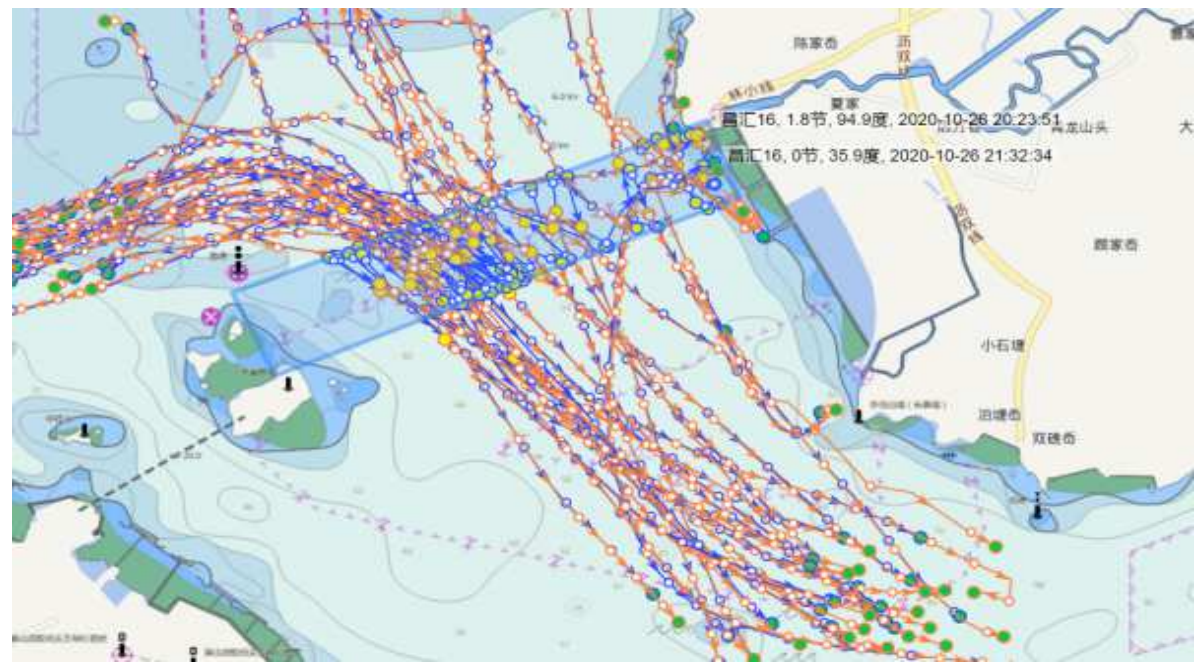

(a) Ship traffic flow chart 


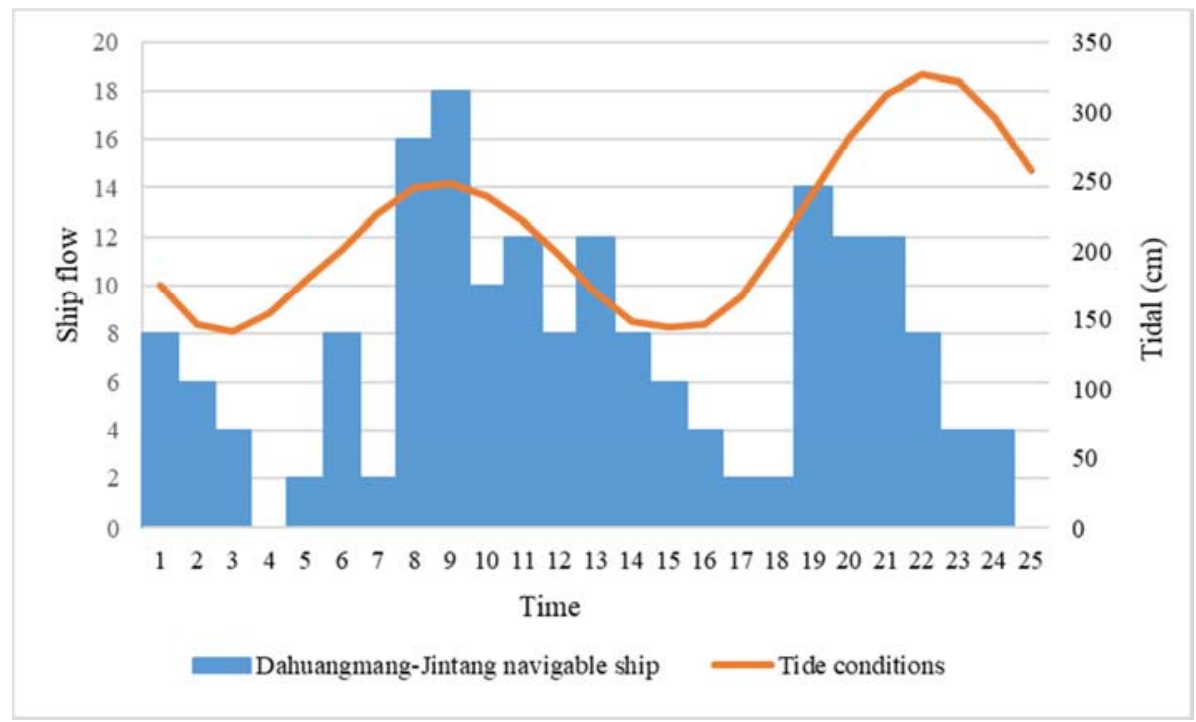

(b) Ship traffic flow statistical chart

Figure 9. Traffic flow from Da Huangmang to Jintang.

Table 4. Statistical tables of ship traffic flows.

\begin{tabular}{llllllllll}
\hline $\begin{array}{l}\text { Type of } \\
\text { ship }\end{array}$ & $\begin{array}{l}\text { Fishing } \\
\text { boat }\end{array}$ & $\begin{array}{l}\text { Engineering } \\
\text { ship }\end{array}$ & $\begin{array}{l}\text { Working } \\
\text { ship }\end{array}$ & $\begin{array}{l}\text { Passenger } \\
\text { ship }\end{array}$ & $\begin{array}{l}\text { Cargo } \\
\text { ship }\end{array}$ & $\begin{array}{l}\text { Dangerous cargo } \\
\text { ship }\end{array}$ & $\begin{array}{l}\text { Other } \\
\text { sips }\end{array}$ & Total & Ship/day \\
\hline Section 1 & 2861 & 973 & 2522 & 47 & 37122 & 5472 & 18387 & 67384 & 184.61 \\
Section 2 & 10186 & 1411 & 10412 & 122 & 61088 & 10759 & 34759 & 128737 & 352.7 \\
Section 3 & 358 & 82 & 3953 & 0 & 2710 & 2883 & 1945 & 11931 & 32.69 \\
\hline
\end{tabular}

It can be seen from the above Figure 8 that the maximum flow rate of ships is the area near Yongjiang Estuary, 128737 ships in total within statistical time, and the average daily flow rate is 352.70 ships/day. The ship flow rate near the berth is the smallest, 11931 ships, and the average daily flow rate is 32.69 ships/day. Therefore, before entering and leaving berths through Jintang waterway, we should first avoid dangerous objects such as Huangniu reefs and goose reefs, pay attention to shallow water areas in the northwest of Qili Anchorage, and be careful of in and outbound vessels at
Yongjiang Estuary and the North channel. And the depth and width of the route can fully meet the requirements of ships entering the Guanbao terminal.

In order to further clarify the relationship between traffic flow and tidal conditions which have a great influence on the berthing operation of the wharf, the traffic flow of the two sections of the Da Huangmang to Jintang and the Da Huangmang to Zhongzhumen and the Xiaomen was counted on October 26,2020. The statistical results are shown in figures 9 and 10, respectively:

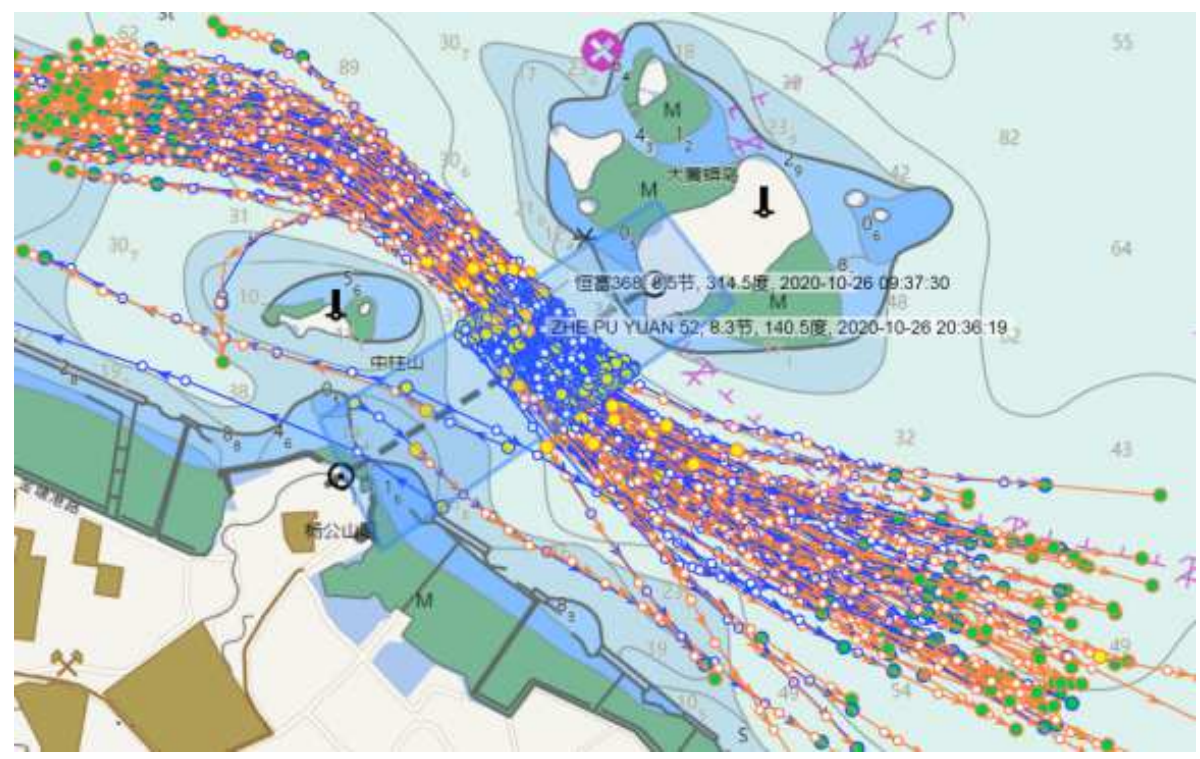

(a) Ship traffic flow chart 


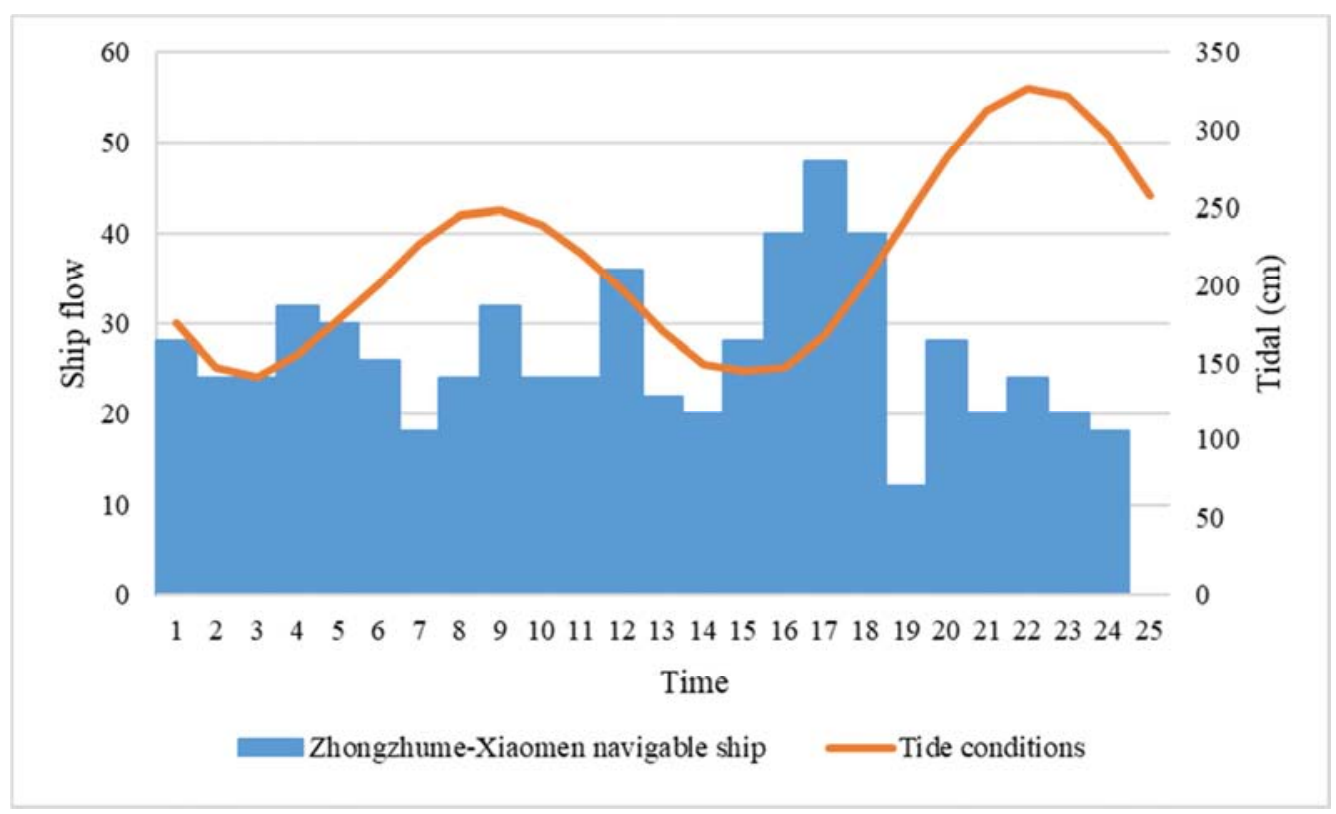

(b) Ship traffic flow statistical chart

Figure 10. Traffic flow from Da Huangmang to Zhongzhumen and the Xiaomen.

It can be found that before and after the high tide of Zhenhai, more ships enter and leave the port through the deep water channel (Da Huangmang to Jintang), while fewer ships enter and leave the port through the deep water channel (Da Huangmang to Jintang) at low tide. However, ships passing through the coastal route near the Guanbao terminal (Da Huangmang to Zhongzhumen, Xioamen) in and out of the port increased significantly when tidal current are fast.

\subsection{Safety of Berthing Operation}

In the course of berthing, the ship is always in the state of motion. In view of the dynamic changes in the movement of the ship, the ship operator must control three segments: the residual speed of berthing, transverse distance and closing angle, make the necessary adjustment to meet the requirements of objective conditions, so that the ship will eventually get alongside smoothly at the designated berth.

Based on the analysis of ship safe berthing evaluation, the moving speed of the berthing ship should not be too fast Therefore, the utility function method can be used to evaluate the safety of ship berthing operation, and the forward speed and transverse speed of the ship under berthing operation can be taken as the target component, take functions synthesized by multiplication and complement the evaluation value. The utility function of ship berthing operation safety evaluation is: [14]

$$
U\left(Z_{1}, Z_{2}\right)=1-\prod_{i=1}^{2}\left(1-Z_{i}\right)^{w_{i}}
$$

In the equation, $U$ is the risk of ship berthing operation; $Z_{1}$ indicates the potential danger of collision when the ship is berthing, and its index factor is the transverse speed $v$ to the wharf; $Z_{2}$ indicates the potential danger of a berthing ship colliding with a ship at berth, and the index factor is the distance $s$ of the berthing ship to the ships ahead and astern; $w_{i}$ is the weight value. If the $Z_{1}, Z_{2}$ utility function curve adopts the intermediate type, the representation methods are as follows: [15]

$$
\begin{aligned}
& Z_{1}= \begin{cases}1 & v \geq v_{1} \\
v / v_{1} & 0<v<v_{1} \\
0 & v=0\end{cases} \\
& Z_{2}= \begin{cases}1 & s \leq 0 \\
1-s / s_{1} & 0<s<s_{1} \\
0 & s \geq s_{1}\end{cases}
\end{aligned}
$$

Formula (6) and formula (7): $v_{1}$ is the limit value of berthing speed determined according to the structure of wharf and the berthing ship; and the $s_{1}$ is the best result value of the distance from the ships ahead and astern at berth (half of the difference between the actual gap of berth and the maximum length of the berthing ship).

The comprehensive evaluation value of ship berthing risk calculated according to the above method and the allowable standard of ship operator are shown in Table 5.

Table 5. Correspondence table between evaluation values and allowable criteria.

\begin{tabular}{lllllll}
\hline allowable criteria & Extremely safe & Safe & Slightly safe & Slightly dangerous & Dangerous & Extremely dangerous \\
\hline Value of indicators & $0 \sim 0.1$ & $0.1 \sim 0.3$ & $0.3 \sim 0.5$ & $0.5 \sim 0.7$ & $0.7 \sim 0.9$ & $0.9 \sim 1$ \\
\hline
\end{tabular}




\section{Examples of Ship Berthing Operation}

Put the ship motion model into the ship-handling simulator, and conduct the berthing operation test in various environments. By setting the ship-handling simulation test in many different navigation environments, obtain the motion parameters and trajectory of the simulated ship. Combined with the potential hazards of ship handling and berthing operation, the safety assessment of navigation environment of wharf engineering for ship handling and berthing is analyzed and evaluated.

On the basis of the average spring tide velocity (rising tidal current $120 \mathrm{~cm} / \mathrm{s}$, falling tidal current $64 \mathrm{~cm} / \mathrm{s}$ ) and the maximum spring tide velocity (rising tidal current $217 \mathrm{~cm} / \mathrm{s}$ falling tidal current $154 \mathrm{~cm} / \mathrm{s}$ ) given in the observed data by hydrological stations close to wharf, combined with the wind data statistics of Zhenhai Youshan Station which has high frequency and great influence on ship berthing for a whole year, the combined working conditions of ship berthing simulation test are established, as shown in Table 6.

Table 6. Experimental data of ship berthing simulation.

\begin{tabular}{llllll}
\hline \multirow{2}{*}{ No. } & State & Wind & \multicolumn{3}{l}{ Current } \\
\cline { 3 - 6 } & & Direction & BF scale & Direction & Speed (kn) \\
\hline 1 & Berthing & ESE & 3 & Rising tide & 2.3 \\
2 & Berthing & NW & 5 & Rising tide & 2.3 \\
3 & Berthing & NNE & 4 & Rising tide & 2.3 \\
4 & Berthing & SSW & 2 & Rising tide & 2.3 \\
5 & Berthing & ESE & 3 & Rising tide & 1.2 \\
6 & Berthing & NW & 5 & Rising tide & 1.2 \\
7 & Berthing & NNE & 4 & Rising tide & 1.2 \\
8 & Berthing & SSW & 2 & Rising tide & 1.2 \\
9 & Berthing & SSW & 6 & Rising tide & 2.3 \\
10 & Berthing & SSW & 7 & Rising tide & 2.3 \\
11 & Berthing & SSW & 6 & Rising tide & 1.2 \\
12 & Berthing & SSW & 7 & Rising tide & 1.2 \\
13 & Berthing & SSW & 8 & Rising tide & 2.3 \\
\hline
\end{tabular}

The number $1-8$ in the table is the ship berthing simulation under normal sea condition, and the number 9-13 is the ship berthing simulation under the extreme sea condition. According to the above 13 working conditions, the simulation results are obtained as shown in Figures 11 and 12 .

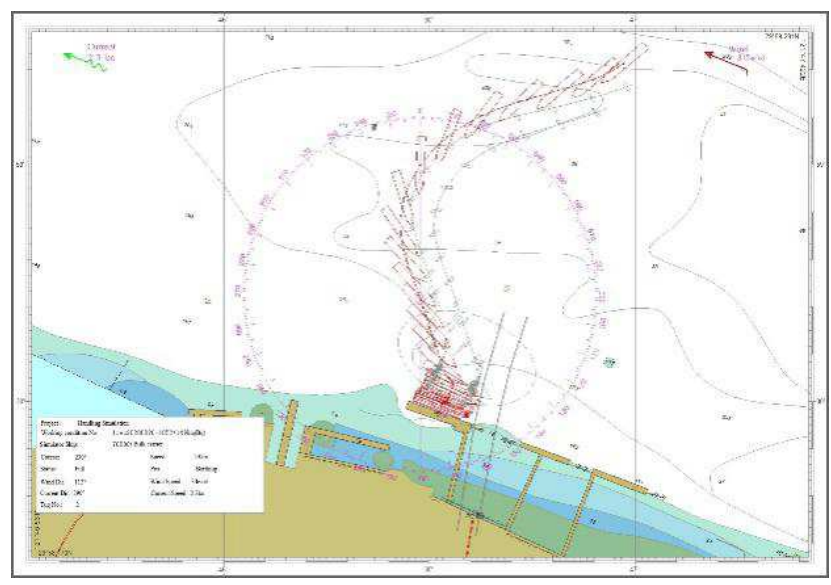

(a) Fully loaded, downwind turn for berthing

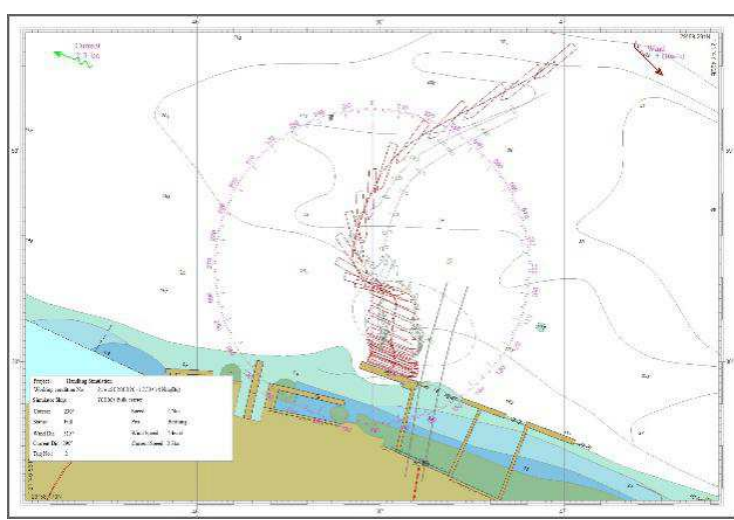

(b) Fully loaded, headwind turn for berthing

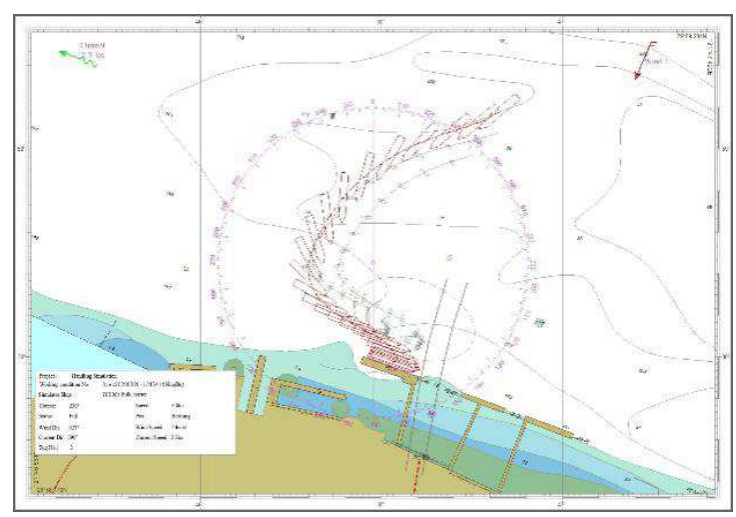

(c) fully loaded, cross wind (onshore wind) turn for berthing

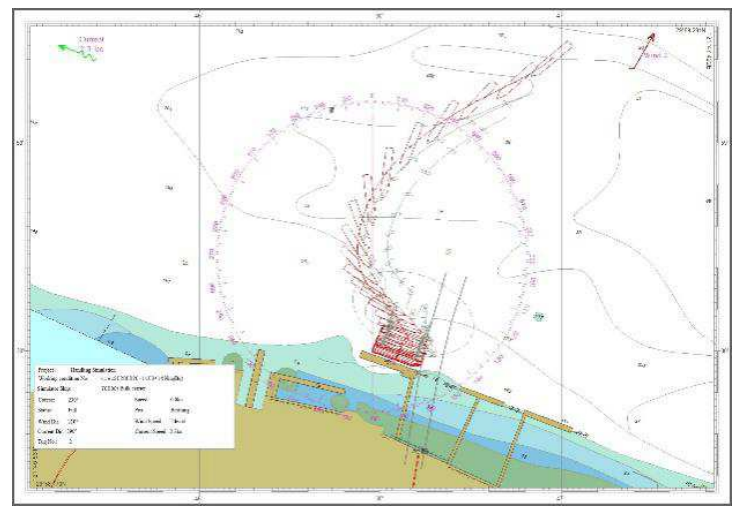

(d) fully loaded, cross wind (offshore wind) turn for berthing

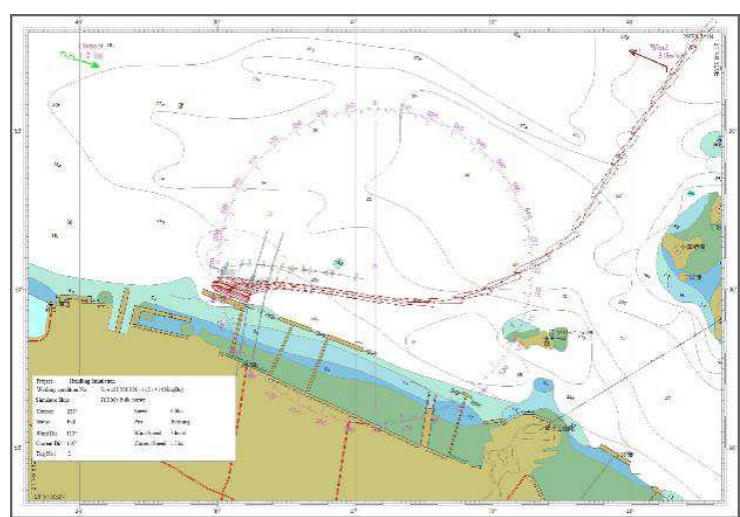

(e) fully loaded, downwind direct for berthing 


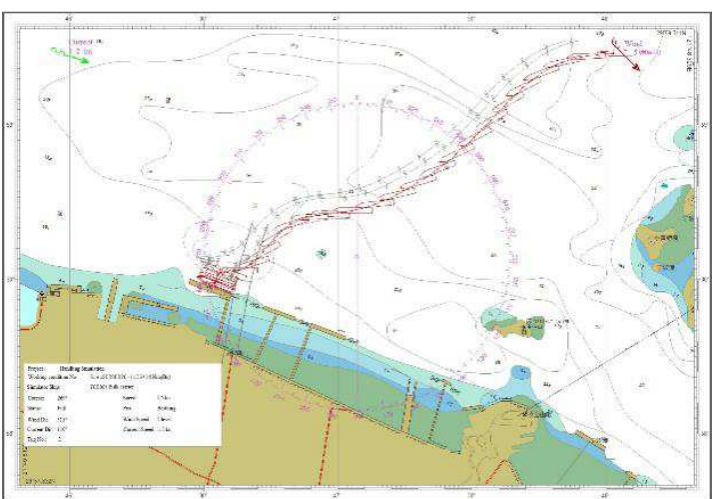

(f) fully loaded, headwind direct for berthing

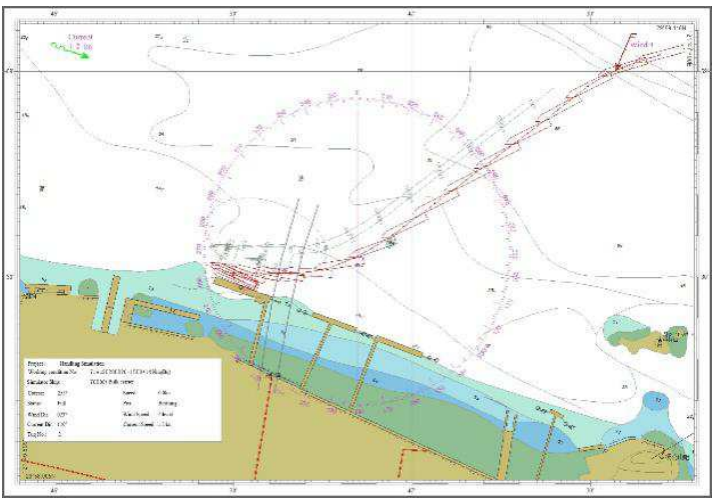

(g) fully loaded, cross wind (onshore wind) direct for berthing

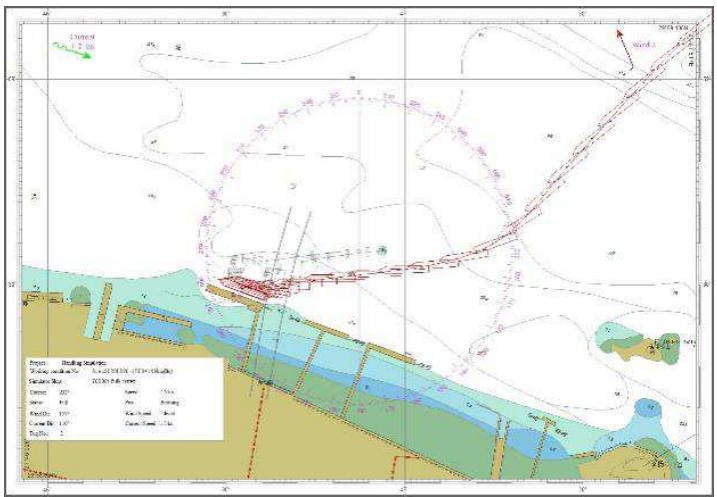

(h) fully loaded, cross wind (offshore wind) direct for berthing

Figure 11. Simulation trajectory of ship berthing under normal sea condition.

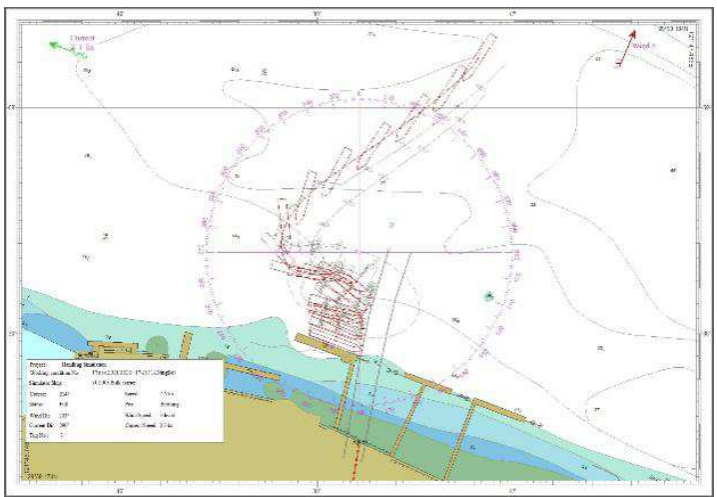

(a) Fully loaded, crosswind (onshore wind BF scale 6) turn for berthing

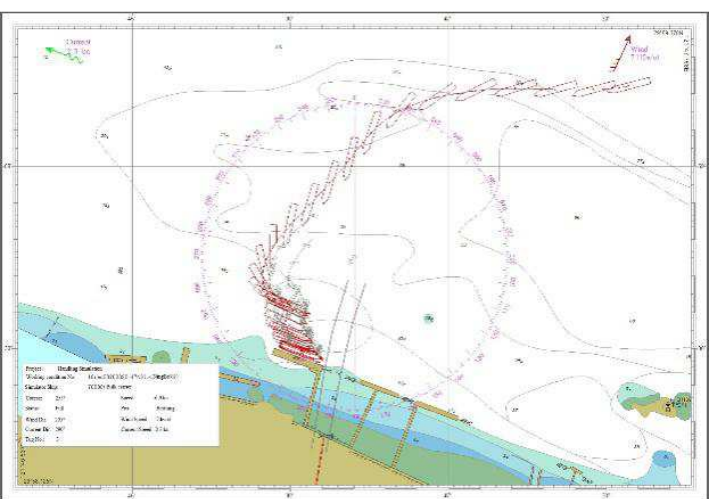

(b) Fully loaded, crosswind (offshore wind BF scale 7) turn for berthing

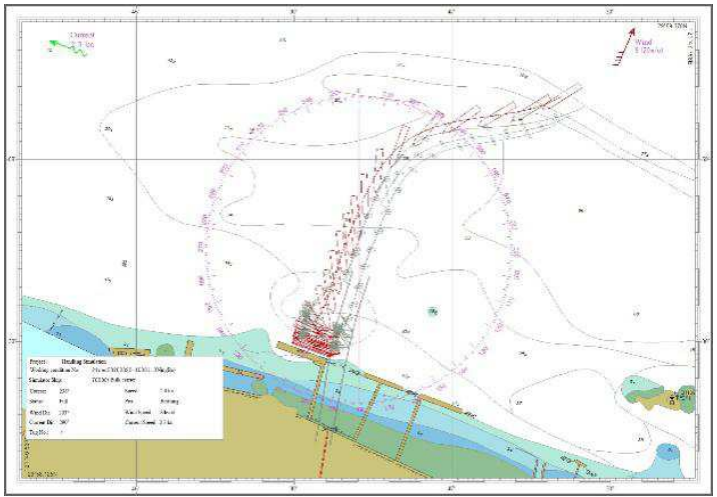

(c) Fully loaded, crosswind (offshore wind BF scale 8) turn for berthing

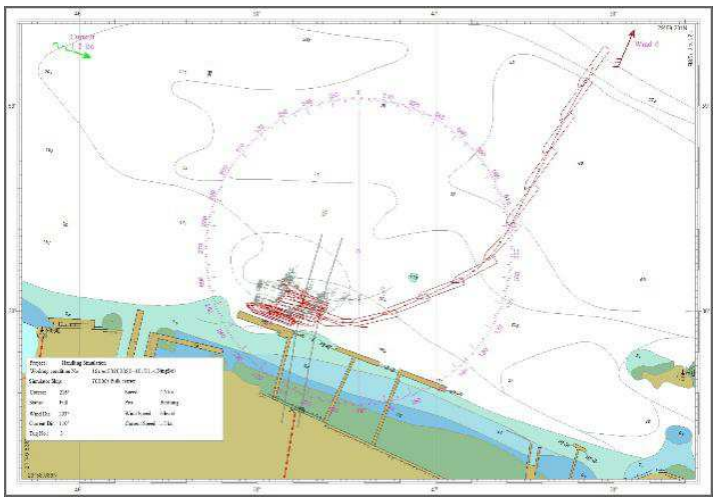

(d) Fully loaded, crosswind (offshore wind BF scale 6) direct for berthing

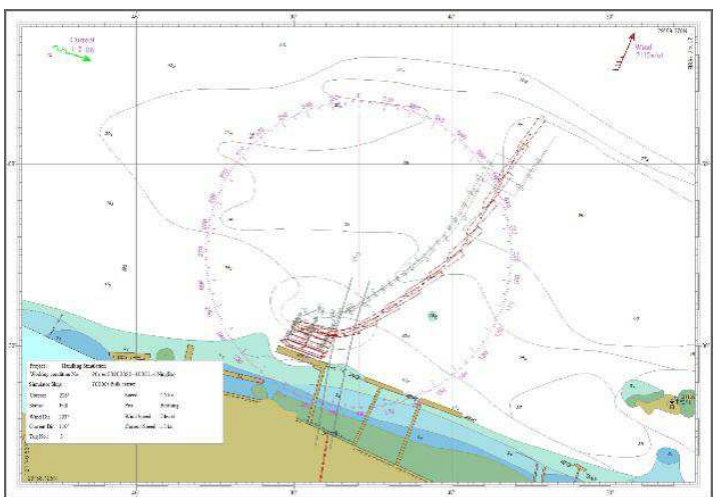

(e) Fully loaded, crosswind (offshore wind BF scale 7) direct for berthing

Figure 12. Simulation trajectory of ship berthing under extreme sea conditions. 
By analyzing the above 8 normal berthing conditions of the ship berthing simulation trajectory map (Figure 11), and use of tugboats and main engine, the following conclusions can be drawn: under normal circumstances, with the assistance of two tugboats, berthing operations can be completed, and it is safer in particular if choosing the time of the end of rising tide and the beginning of falling tide (slow tidal current). In addition, because the turning area at the front of the wharf is not large, it is suggested to select the time of the end of rising tide for berthing, and that the tug should be used in advance to assist the turning against the rising tidal current. At the time the end of rising tide, a large number of ships will proceed in and out of Yongjiang Estuary, making the traffic more complicated, so it is not suitable to move the ship to the west too far. Guanbao wharf is located on the west side of Qingshi Chemical Wharf, If berthing at the time of the beginning of falling tide, the available operating waters will be sufficient and much safer.

Through the simulation test, under the wind condition of BF scale 6 , especially when the ship is affected by crosswind, it is necessary to increase the power of tugs or increase the number of tugs for safe berthing compared to normal berthing operation (2 tugs, 3900 horsepower each). In case that the wind force exceeds the limit of BF scale 7, the risk will be greatly increased. In view of the above situation, it is suggested that the berthing operation should be controlled below wind scale 6 as far as possible.

Taking the simulation as shown in Figure 11(a) as an example, the current direction is $275^{\circ}$, speed $2.3 \mathrm{kn}$, wind direction is $112.5^{\circ}$, wind force $\mathrm{BF} 3$, berth length is $120 \%$ length of the ship, and keep the closing angle of the ship to the berth at $0^{\circ}$ as far as possible when the ship is $100 \mathrm{~m}$ away from the berth. According to structure of the ship and wharf, $v_{1}=5 \mathrm{~cm} / \mathrm{s}$; According to the length of berth, $s_{1}=42.5 \mathrm{~m}$; Weight value $w_{1}$ and $w_{2}$ are 0.4 and 0.6 respectively. Taking the transverse velocity $v$ and the average value $s$ of the nearest distance to the ships forward and astern when the ship is $100 \mathrm{~m}$ from the berth to calculate $Z_{1}$ and $Z_{2}$, the risk of berthing operation under set conditions can be obtained as:

$$
U=1-(1-0.25)^{0.4} \times(1-0.30)^{0.6}=0.28
$$

Referring to the values in Table 6 , it can be found that the ship berthing is in a safe state. Through simulation and evaluation, the risk degree of ship berthing operation under different conditions can be obtained, which provides important reference data for optimizing berthing scheme and safety precautions of wharf engineering.

\section{Conclusion}

Ship-handling simulator has been widely used and playing an important role in maritime education and training, analysis of maritime accident cause and engineering design evaluation. In this paper, the parameters and trajectory of the simulated ship are obtained by setting the simulation test of ship berthing operation under navigational environment, and the concepts of potential ship-handling water area and risk degree of berthing operation are applied to analyze and evaluate the channel width, ship turning water area and berthing safety operation required for the safety assessment of navigation environment of wharf engineering. The practical application shows that this method is objective, feasible and reasonable to analyze and evaluate the navigation safety of wharf engineering, and has a good value of application.

\section{References}

[1] Inoue K, Okazaki T, Murai K, et al. Fundamental Study of Evaluation at Berthing Training for Pilot Trainees Using a Ship Maneuvering Simulator [J]. Transnav International Journal on Marine Navigation \& Safety of Sea Transportation, 2013, 7 (2): 135-141.

[2] Davidson K., Schiff L. Turning and course keeping qualities of ships [J]. Society of Naval Architects and Marine Engineers, 1946, 54 (8): 152-200.

[3] Abkowitz M A. Measurement of hydrodynamic characteristics from ship maneuvering trials by system identification [J]. Transactions of SNAME, 1980, 88: 283-318.

[4] Jia Xingle, Yang Yansheng. Mathematical Model of Ship Motion - Mechanism and Identification Modeling [M]. Dalian Maritime University Press, 1999. (In Chinese).

[5] Yasukawa H, Sakuno R. Application of the MMG method for the prediction of steady sailing condition and course stability of a ship under external disturbances [J]. Journal of Marine Science and Technology, 2019.

[6] Xiaobin J. Research on Modeling, Simulation and Application of Ship Mooring System [D], Dalian Maritime University, 2020 .

[7] Zhang Xiufeng, Hong Biguang, Jin Yicheng. Application of Ship Handling Simulator in Ship Navigation Safety Assessment [J]. Maritime China, 2003 (03): 26-28+33.

[8] Zhang Shougui, Weng Yuezong, Xiong Zhennan. Safety Assessment of Port Channels and Terminals [J]. Journal of Dalian Maritime University, 2006 (04): 43-47.

[9] Jin Yicheng, Yin Yong. Navigation Simulator [M]. Beijing: Science Press, 2013, 53-56.

[10] Isherwood R M. Wind resistance of merchant ships [J]. Royal Institution of Naval Architects, 1973, 115: 327-338.

[11] Ministry of Transport of the People's Republic of China. China Sea Port General Design Code [S]. Beijing: People's Transport Press, 2003.

[12] Fang Xianglin, et al. Ship Traffic and Handling Safety System Evaluation Model and Method [M]. Dalian: Dalian Maritime University Press, 2003.

[13] Liu C, Liu J, Zhou X, et al. AIS data-driven approach to estimate navigable capacity of busy waterways focusing on ships entering and leaving port [J]. Ocean Engineering, 2020, 218: 108215. 
[14] Liu Hongyu, Chen Hongbo, Hao Yanling. A Collision Hazard Model Based on Fuzzy Principle [J]. Maritime China, 1998, (2): 23-29.
[15] Yao Jie, Wu Zhaolin, Fang Xianglin. Adaptive Neural Network for Ship Collision Hazard -- Fuzzy Inferential Evaluation Method [J]. Maritime China, 1999, (1): 14-19. 